\title{
How to Perform and Interpret Balloon Expulsion Test
}

\author{
Bong Eun Lee and Gwang Ha Kim* \\ Department of Internal Medicine, Pusan National University School of Medicine, Busan, Korea
}

The balloon expulsion test is a simple and useful method for investigating a defecatory disorder assessing the subject's ability to evacuate a simulated stool. However, there is no standard methodology and varying interpretations have been reported. This review discusses the techniques, interpretation and clinical utility of the balloon expulsion test.

(J Neurogastroenterol Motil 2014;20:407-409)

Key Words

Constipation; Defecation; Functional gastrointestinal disorders

\section{Introduction}

The balloon expulsion test (BET) is a simple and inexpensive bedside procedure that can identify patients with pelvic floor dyssynergia. However, there is no standardization in the methodology such as the filling volume of the balloon or the position of the patient for BET. ${ }^{1}$ In addition, the normal range of balloon expulsion time has differed in various studies and laboratories. This review discusses the techniques, interpretation and clinical utility of this examination.

\section{How to Perform a Balloon}

\section{Expulsion Test}

The BET provides an assessment of the subject's ability to evacuate artificial stool during simulated defecation within the laboratory environment (Figure). ${ }^{2-4}$ The examination can be conducted as part of anal manometry or as an isolated investigation.

\section{Standard Procedure}

\section{Devices}

Mostly, this simple test just requires a latex balloon attached to a catheter with a water-filled syringe to inflate the balloon.

\section{Preparation}

Patients are recommended to receive 1 or 2 cleansing enemas several hours before the procedure. Actually, rectal cleansing is not necessary for the examination itself. However, since patients usually worry about the occurrence of real defecation during the

Received: May 31, 2014 Revised: June 4, 2014 Accepted: June 5, 2014

(c) This is an Open Access article distributed under the terms of the Creative Commons Attribution Non-Commercial License (http://creativecommons. org/licenses/by-nc/3.0) which permits unrestricted non-commercial use, distribution, and reproduction in any medium, provided the original work is properly cited.

*Correspondence: Gwang Ha Kim, MD

Department of Internal Medicine, Pusan National University School of Medicine and Biomedical Research Institute, Pusan National University Hospital, 179, Gudeok-ro, Seo-gu, Busan 602-739, Korea

Tel: +82-51-240-7869, Fax: +82-51-244-8180, E-mail: doc0224@pusan.ac.kr

Financial support: This work was supported by a Pusan National University Hospital Clinical Research Grant (2014).

Conflicts of interest: None.

ORCID: Gwang Ha Kim, http://orcid.org/0000-0001-9721-5734. 

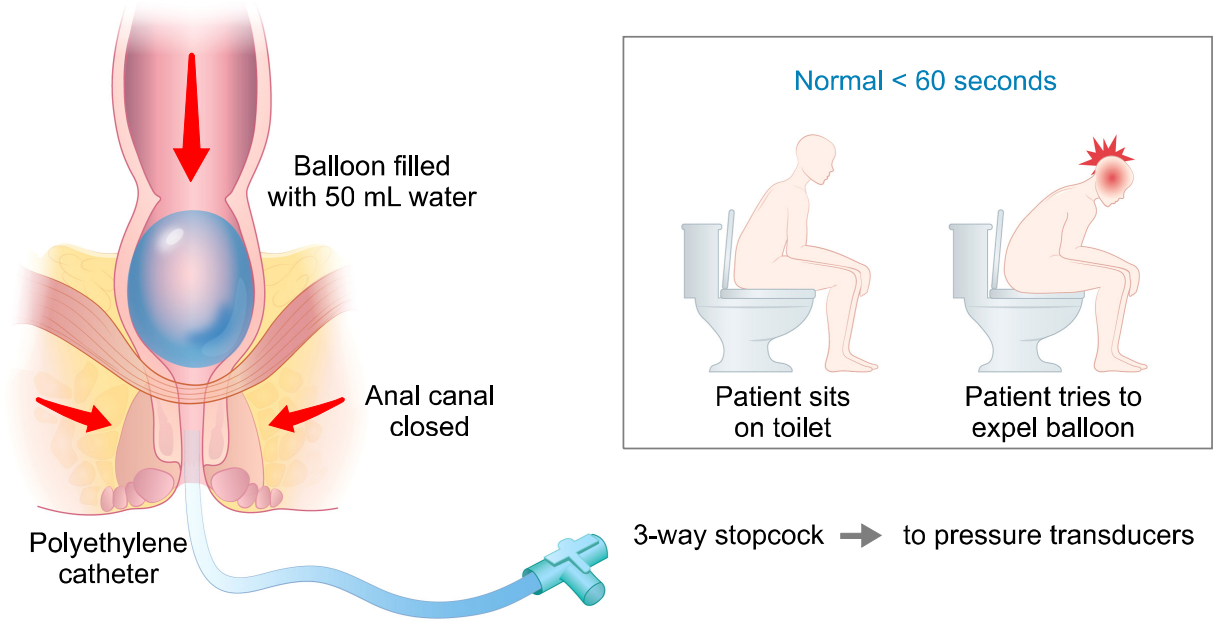

3-way stopcock $\rightarrow$ to pressure transducers test, performing rectal preparation is regarded to be more comfortable for patients.

\section{Techniques}

Patients are initially placed in a left lateral decubitus position with flexion of the knees and hips. After well lubricated empty balloon is gently inserted into the rectum, the balloon is inflated by a fixed volume, typically $50 \mathrm{~mL}$ of water, or alternatively until the patients feel a desire to defecate. Patients are then asked to attempt to evacuate the balloon in the sitting position in privacy.

\section{Special Considerations}

\section{Types of the balloon and instilled material into the balloon}

Since the methodology for BET has not been standardized as noted above, different types of balloon other than rubber balloon have been used including $18 \mathrm{~mm}$ spheres or silicone-filled stool-like device (FECOM). And some laboratories instill the balloon with the air instead of the water. ${ }^{1}$

\section{Filling volume of the balloon}

In addition to rectal evacuation, perception of desire to defecate is essential for normal defecation, especially for the beginning and maintenance of defecation. While most laboratories inflate a rectal balloon by a standard volume, typically $50 \mathrm{~mL}$, it has been reported that when rectal sensation is reduced, patients may not perceive the desire to defecate at a volume of $50 \mathrm{~mL}$, limiting the ability to evacuate the balloon even though rectal evacuation is preserved. $^{5}$ That is, low volume insufficient to achieve a desire to defecate would result in overdiagnosis of a defecation disorder. Based on this observation, some recent studies suggested to inflate the balloon to the point at which the patients experience the desire to defecate. ${ }^{5}$ However, testers need to consider the possibility that it could be more difficult for patients with a defecatory disorder to expel a larger balloon. ${ }^{6}$ And these 2 techniques (i.e., fixed versus variable balloon inflation) have not been yet compared.

Meanwhile, one recent study recommended a FECOM with the result that stool-like sensation was more commonly evoked by FECOM than balloon. ${ }^{7}$

\section{Position of the patient during defecation}

In some laboratories, balloon evacuation is conducted in the left lateral decubitus position, wherein a rectal balloon is connected over a pulley to weights, which provides external traction when necessary to facilitate expulsion of rectal balloon. ${ }^{8}$ However, recent studies and laboratories suggested that sitting position appears to be more conductive for defecation than the lying position showing that $36 \%$ of normal healthy subjects exhibited a dyssynergic pattern in the lying position. ${ }^{7}$ Since sitting is an actual defecation posture and provides more driving force to defecate, it is desirable for patients to perform the balloon evacuation in the sitting position. And also, balloon evacuation should be done in a private setting. Because the test is fully conducted by patients' voluntary efforts, it is important to provide the patients with a relaxed and comfortable environment to obtain a correct result. 
other anorectal physiologic studies.

\section{How to Interpret the Balloon Expulsion Time and Its Clinical Utility}

Balloon expulsion time allowed for patients has differed according to the studies and laboratories. Since most normal subjects can expel the balloon within 1 minute, recent studies provide that inability to expel the balloon within 1 minute is suggestive of a defecatory disorder. ${ }^{2,9}$ Under the circumstances with left lateral decubitus position, normally, expulsion can be achieved spontaneously or with the addition of less than $100 \mathrm{~g}$ of weight. ${ }^{6}$

The prevalence of abnormal BET in favor of constipation varies between 23 and $67 \%$. ${ }^{1}$ One study reported a sensitivity of $88 \%$, a specificity of $89 \%$, a positive predictive value of $67 \%$ and a negative predictive value of $97 \%$ for this test and suggested a normal BET might exclude a defecatory disorder. ${ }^{5}$ However, Rao et $\mathrm{al}^{10}$ found that many patients with dyssynergia could expel the balloon and they described a contradictory view that a normal test could not exclude the possibility of a defecatory disorder. ${ }^{1,11}$ Around $0-16 \%$ of healthy controls had difficulty in evacuating the balloon ${ }^{1}$ which means that the test itself was insufficient to make a diagnosis of a defecatory disorder.

Although the failure to expel a balloon strongly suggests the possibility of pelvic floor dyssynergia, a normal test dose not exclude this possibility. In addition, this simple test does not define the structural abnormality of anorectum and mechanisms of disordered defecation. Therefore, this test should be integrated along with other anorectal physiologic tests.

Some studies reported a capability of BET for predicting the outcomes in patients following biofeedback therapy ${ }^{12-14}$ and further studies are necessary regarding this issue.

\section{Conclusions}

The BET is a simple test widely used for diagnosing a defecatory disorder. Although the result of the test is binary (i.e., normal or abnormal), interpretation is not easy and should be done with caution. In conclusion, the BET is not a sole diagnostic test for a defecatory disorder, and must be used in conjunction with

\section{References}

1. Rao SS, Ozturk R, Laine L. Clinical utility of diagnostic tests for constipation in adults: a systematic review. Am J Gastroenterol 2005;100:1605-1615.

2. Rao SS. Constipation: evaluation and treatment of colonic and anorectal motility disorders. Gastroenterol Clin North Am 2007;36:687711, $\mathrm{x}$.

3. Bharucha AE, Fletcher JG. Recent advances in assessing anorectal structure and functions. Gastroenterology 2007;133:1069-1074.

4. Ballon expulsion test. Rome computer-based learning program on functional gastrointestinal disorders. Available from URL: http:// www.romecriteria.org/pdfs/ AllSlides_Pictures.pdf (accessed May 2014).

5. Minguez M, Herreros B, Sanchiz V, et al. Predictive value of the balloon expulsion test for excluding the diagnosis of pelvic floor dyssynergia in constipation. Gastroenterology 2004;126:57-62.

6. Ratuapli S, Bharucha AE, Harvey D, Zinsmeister AR. Comparison of rectal balloon expulsion test in seated and left lateral positions. Neurogastroenterol Motil 2013;25:e813-e820.

7. Rao SS, Kavlock R, Rao S. Influence of body position and stool characteristics on defecation in humans. Am J Gastroenterol 2006;101: 2790-2796.

8. Pezim ME, Pemberton JH, Levin KE, Litchy WJ, Phillips SF. Parameters of anorectal and colonic motility in health and in severe constipation. Dis Colon Rectum 1993;36:484-491.

9. Rao SS, Hatfield R, Soffer E, Rao S, Beaty J, Conklin JL. Manometric tests of anorectal function in healthy adults. Am J Gastroenterol 1999;94:773-783.

10. Rao SS, Mudipalli RS, Stessman M, Zimmerman B. Investigation of the utility of colorectal function tests and Rome II criteria in dyssynergic defecation (Anismus). Neurogastroenterol Motil 2004;16: 589-596.

11. Rao SS, Meduri K. What is necessary to diagnose constipation? Best Pract Res Clin Gastroenterol 2011;25:127-140.

12. Loening-Baucke V. Factors determining outcome in children with chronic constipation and faecal soiling. Gut 1989;30:999-1006.

13. Fernández-Fraga X, Azpiroz F, Casaus M, Aparici A, Malagelada JR. Responses of anal constipation to biofeedback treatment. Scand J Gastroenterol 2005;40:20-27.

14. Shin JK, Cheon JH, Kim ES, et al. Predictive capability of anorectal physiologic tests for unfavorable outcomes following biofeedback therapy in dyssynergic defecation. J Korean Med Sci 2010;25:10601065 . 